Изучение влияния воздействия высокочастотной акустической
кавитации на качество молока-сырья и молочных продуктов
на его основе

\begin{tabular}{|c|c|c|c|c|}
\hline & $\begin{array}{l}\text { Ксения А. Канина } \\
\text { Ольга Н. Красуля } \\
\text { Николай А. Жижин } \\
\text { Елена С. Семенова }\end{array}$ & $\begin{array}{l}1 \\
2 \\
2\end{array}$ & $\begin{array}{l}\text { kseniya.kanina.91@mail.ru } \\
\text { okrasulya@mail.ru } \\
\text { zhizhinmoloko@mail.ru } \\
\text { semenovamoloko@mail.ru }\end{array}$ & $\begin{array}{l}\text { (D) } 0000-0002-8833-4915 \\
\text { (D) } 0000-0002-6234 \\
\text { (D) } 0000-0002-6690-0488\end{array}$ \\
\hline $\begin{array}{l}{ }^{1} \text { Российский Гос) } \\
127550, \text { Россия } \\
{ }^{2} \text { ВНИИ молочної }\end{array}$ & $\begin{array}{l}\text { енный аграрный универс } \\
\text { шленности, ул. Люсинов }\end{array}$ & & $\begin{array}{l}\text { МСХА имени К.А. Тимирязева, ул. } \\
\text { 5/7, г. Москва, } 115093, \text { Россия }\end{array}$ & \\
\hline
\end{tabular}

Аннотация. Приведены результаты исследований, полученных при изучении качества молока, обработанного с применением высокочастотной акустической кавитации, и молочных продуктов, выработанных с его использованием. Исследования выполнялись с применением общенаучных и специальных методов исследований в лаборатории кафедры технологии хранения и переработки продуктов животноводства РГАУ-МСХА имени К. А. Тимирязева и в аккредитованной лабораторией технохимического контроля ФГАНУ «Всероссийский научно-исследовательский институт молочной промышленности». Показано, что при обработке коровьего молока-сырья высокочастотными ультразвуковыми колебаниями (свыше 45 кГц), генерируемыми электрическим ультразвуковым прибором погружного типа импульсного воздействия УЗО «Активатор-150», количество бактерий группы кишечной палочки (БГКП) снизилось почти на $40 \%$, что позволяет сделать вывод о целесообразности выбранного способа воздействия для уничтожения микроорганизмов группы кишечной палочки и колиформных бактерий. Обработанное с применением высокочастотной акустической кавитации коровье молоко использовалось для производства рассольного сыра - брынзы. Показано, что брынза обладает высокой пищевой ценностью, которая обусловлена сохранением эссенциальных веществ в сырье (в частности, кальция, который при производстве брынзы выпадает в осадок, если используется пастеризованное молоко), упругой консистенцией, безопасностью потребительских характеристик - микробиологических и физико-химических.

Ключевые слова: коровье молоко, акустическая кавитация, микробиологический фон, качественные характеристики молока, сыр брынза, показатели безопасности сыра-брынзы

\title{
Study of the effect of high-frequency acoustic cavitation on the quality of raw milk and dairy products based on it
}

\begin{tabular}{|c|c|c|}
\hline $\begin{array}{l}\text { Ksenia A. Kanina } \\
\text { Olga N. Krasulya } \\
\text { Nikolay A. Zhizhin } \\
\text { Elena S. Semenova } \\
\end{array}$ & $\begin{array}{l}\text { kseniya.kanina.91@mail.ru } \\
\text { okrasulya@mail.ru } \\
\text { zhizhinmoloko@mail.ru } \\
\text { semenovamoloko@mail.ru }\end{array}$ & $\begin{array}{l}\text { (D) } 0000-0002-8833-4915 \\
\text { (D) } 0000-0002-6234 \\
\text { (D) } 0000-0002-6690-0488\end{array}$ \\
\hline \multicolumn{3}{|c|}{$\begin{array}{l}1 \text { Russian State Agrarian University - Moscow Timiryazev agricultural Academy, Timiryazevskaya st., 49, Moscow, 127550, Russia } \\
2 \text { All-Russian Research Institute of Dairy Industry, lyusinovskaya str., 35/7, Moscow, 115093, Russia }\end{array}$} \\
\hline \multicolumn{3}{|c|}{$\begin{array}{l}\text { Abstract. The article presents the results of studies obtained in the study of the quality of milk processed with the use of high-frequency } \\
\text { acoustic cavitation and dairy products produced with its use. The research was carried out with the use of General scientific and special } \\
\text { research methods in the laboratory of the Department of technology of storage and processing of animal products of the K. A. } \\
\text { Timiryazev and in the accredited laboratory of technochemical control of the all-Russian research Institute of dairy industry. It is shown } \\
\text { that the treatment of cow's milk-raw materials high-frequency ultrasonic vibrations (above } 45 \mathrm{kHz} \text { ), the generated electric ultrasonic } \\
\text { device immersion type pulse impact ouzo "Activator-150", the number of bacteria of group of intestinal sticks (coliforms) decreased } \\
\text { by almost } 40 \% \text {, which allows to make a conclusion about the appropriateness of the selected method of exposure for the destruction of } \\
\text { microorganisms E. coli and coliform bacteria. Processed, using high-frequency acoustic cavitation, cow's milk was used for the } \\
\text { production of brine cheese-cheese. It is shown that cheese cheese had a high nutritional value, which is due to the preservation of } \\
\text { essential substances in the raw material (in particular, calcium, which in the production of cheese cheese precipitates if pasteurized } \\
\text { milk is used), elastic consistency, safety of consumer characteristics - microbiological and physico-chemical. }\end{array}$} \\
\hline
\end{tabular}

Для цитирования

Канина К.А., Красуля О.Н., Жижин Н.А., Семенова Е.С. Изучение влияния воздействия высокочастотной акустической кавитации на качество молока-сырья и молочных продуктов на его основе // Вестник ВГУИТ. 2019. Т. 81. № 3. С. 145-150. doi:10.20914/23101202-2019-3-145-150

\section{For citation}

Kanina K.A., Krasulya O.N., Zhizhin N.A., Semenova E.S. Study of the effect of high-frequency acoustic cavitation on the quality of raw milk and dairy products based on it. Vestnik VGUIT [Proceedings of VSUET]. 2019. vol. 81. no. 3. pp. 145-150. (in Russian). doi:10.20914/2310$1202-2019-3-145-150$

This is an open access article distributed under the terms of the Creative Commons Attribution 4.0 International License 


\section{Введение}

В настоящее время для получения качественных и безопасных молочных продуктов используют множество различных методов обработки молока-сырья: пастеризация, стерилизация, ультрапастеризация, а также кавитация, обработка озоном, электромагнитным излучением и т. Д., в оценке эффективности которых решающую роль играет уменьшение степени бактериальной обсемененности молока-сырья и сохранение биологической ценности продукта [16].

Наиболее распространенным методом обработки молока-сырья в России является пастеризация и стерилизация. Однако эти способы являются энергоемкими, требуют определенного аппаратурного оформления и соответствующих площадей. В качестве альтернативы вышеназванным способам в зарубежной практике используются акустические и электромагнитные методы обработки восстановленного молока и молочной сыворотки $[14,18,19]$. В доступных источниках информации практически отсутствуют сведения о влиянии высокочастотной акустической обработки на качество и безопасность цельного коровьего молока, а также о возможности его использования при выработке молочных продуктов.

Учитывая вышеизложенное, изучение влияния обработки молока-сырья с применением физико-химических методов - высокочастотной акустической обработки - является актуальным научным направлением.

Цель работы - изучение влияния высочастотной акустической кавитации на коровье молоко-сырье для достижения определенного пастеризационного эффекта с последующим его использованием при производстве молочных продуктов.

\section{Материалы и методы}

В качестве объектов исследования использовали коровье молоко, полученное от черно-пестрой породы коров. Обработку молока проводили с учетом воздействия бактерицидной фазы. Полученное молоко после доения для прохождения бактерицидной фазы хранили при температуре в диапазоне 0 до $+2{ }^{\circ} \mathrm{C}$ в течение 2-3 ч, а затем осуществляли высокочастотное акустическое воздействие.

В качестве высокочастотного генератора ультразвуковых колебаний использовали ультразвуковой прибор погружного типа импульсного воздействия УЗО «Активатор-150» (рисунок 1).

Для оценки качественных характеристик молока и молочных продуктов применялись следующие методы:

- определение массовой доли жира ГОСТ 5867-90;

- определение массовой доли белка - ГОСТ 23327-98;
$3625-84$

- определение плотности молока - ГОСТ

- определение кислотности молока, ${ }^{\circ} \mathrm{T}-$ ГОСТ 3624-92;

- определение массовой доли влаги ГОСТ 3626-73.

- определение термоустойчивости молока по ГОСТ 25228-82;

- определение жирнокислотного состава молока и молочных продуктов проводилось в соответствии с ГОСТ 32915-2014 «Молоко и молочная продукция» методом высокоэффективной газожидкостной хроматографии;

Органолептическая оценка проводилась в соответствии с ГОСТ 33630-2015. Определение афлатоксина M1 проводилось в соответствие с ГОСТ 33601-2015.

Микробиологические показатели:

- общее количество мезофильных анаэробных и факультативно-анаэробных определялось по ГОСТ 32901-2014 [3];

- бактерии группы кишечной палочки в соответствии с ГОСТ 32901-2014;

- споры мезофильных аэробных микрорганизмов при $30^{\circ} \mathrm{C}$ в $1 \mathrm{~cm}^{3}$ - согласно ГОСТ 32901-2014.

Определение сычужной свертываемости проводили по сычужно-бродильной пробе ГОСТ 32901-2014; Определение токсичных элементов осуществлялось в соответствии с ГОСТ Р 30178-96. Определение антибиотиков осуществлялось с помощью иммуноферментного анализа с хемилюминесцентной детекцией с использованием технологии биочипов на приборе фирмы Randox [20, 21].

\section{Результаты и обсуждение}

Результаты исследования показывают, что при обработке высокочастотными ультразвуковыми колебаниями (свыше 45 кГц), генерируемыми электрическим ультразвуковым прибором погружного типа импульсного воздействия УЗО «Активатор-150», количество бактерий группы кишечной палочки (БГКП) снизилось почти на $40 \%$, что позволяет сделать вывод об эффективности выбранного способа воздействия для уничтожения санитарно-патогенной (показательной) микрофлоры в молоке-сырье и достижении определенного пастеризационного эффекта. Проведена оценка качественных характеристик брынзы, полученной из коровьего молока, подвергнутого воздействию высокочастотной акустической кавитации (таблица 1). Технологическая схема производства брынзы с применением технологии акустической кавитации предусматривает операцию «высокочастотная кавитационная обработка молока (объем $20000 \mathrm{~cm}^{3}$ ) с применением прибора УЗО «Активатор-150» при мощности воздействия не менее 1,5-2,0 кВт. Время воздействия составляет от 30 до 60 мин в зависимости от общей бактериальной обсемененности молока (ККТ - критическая контрольная точка). Взамен 
операции «пастеризация» предложено осуществлять термизацию молока при температуре 60-65 ${ }^{\circ} \mathrm{C}$, в течение 25-30 мин (ККТ-критическая контрольная точка).

Результаты пробы коровьего молока, подвергнутого воздействию высокочастотной акустической кавитации, на сыропригодность свидетельствуют, что предварительная обработка молока-сырья не оказывает негативного влияния на качество сгустка; сгусток имеет ровную поверхность, с достаточно большим уровнем синерезиса и его можно отнести к первому классу по сыропригодности.

Известно, что пастеризация является энергоемким процессом и требует больших площадей для ее осуществления [15]. Применение высокочастотной акустической кавитации на стадии обработки молока-сырья позволяет в дальнейшем при термизации значительно уменьшить тепловую нагрузку на сырье и, тем самым, сохранить его высокую биологическую ценность и, кроме того, сэкономить значительное

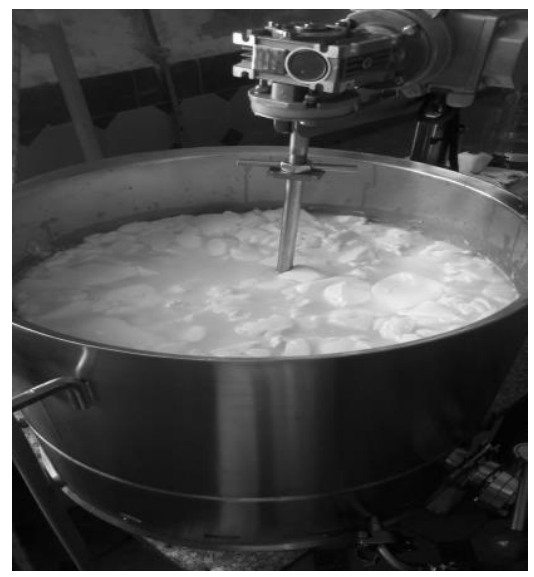

количество электроэнергии, т. е. способствовать энергосбережению.

Согласно работе [15] при пастеризации молока кальций, важный компонент для образования сырного сгустка, выпадает в осадок, что приводит к ослаблению его упругости. При высокочастотном кавитационном воздействии на молоко-сырье, по-видимому, этот процесс не происходит, так как сформированный сырный сгусток (опыт) обладает упругой консистенции (рисунки 1, 2), в отличие от сырного сгустка, полученного из пастеризованного молока (контроль). При этом не происходит заметного изменения (в сторону ухудшения) физикохимических и органолептических показателей опытного образца сыра по сравнению с контролем (таблица 1), что позволяет сделать вывод о технологической целесообразности применения высокочастотной кавитационной обработки молока-сырья при производстве рассольного сыра - брынзы.

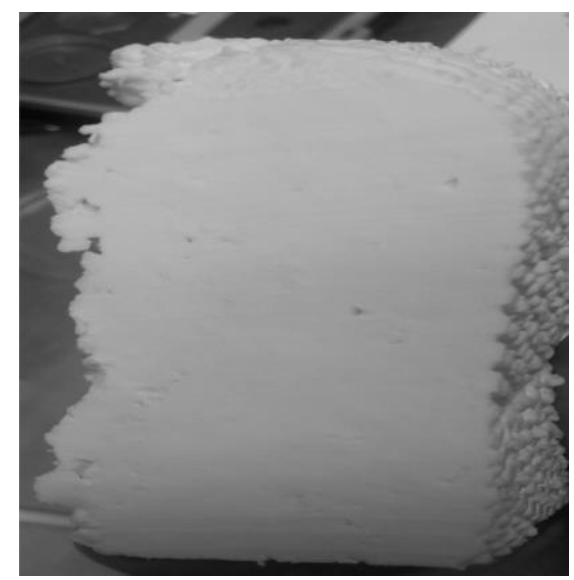

Рисунок 1. Процесс вымешивания сырного серна; снизу - в разрезе брынза после прессования Figure 1. Process of kneading cheese chamois; bottom -in the section cheese after pressing
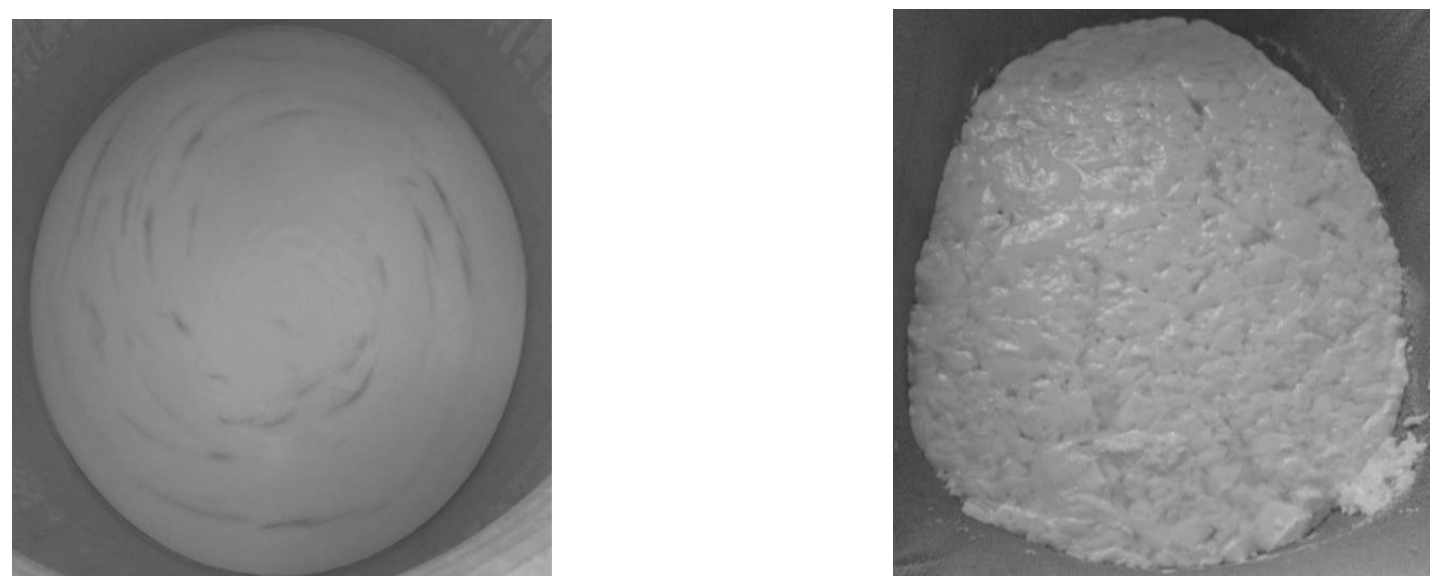

Рисунок 2. Процесс образования сгустка рассольного сыра - брынзы: сверху - из молока, подвергнутого высокочастотной кавитационной обработке; снизу - вид сгустка из пастеризованного молока в разрезе

Figure 2. Process of formation of a clot of brine cheese: from above - from milk subjected to high-frequency cavitation treatment; from below - view of a clot of pasteurized milk in the section 
Физико-химические показатели брынзы, полученной из коровьего молока, подвергнутого воздействию высокочастотной акустической кавитации

Table 1.

Physical and chemical parameters of brine cheese cheese obtained from cow's milk exposed to high-frequency acoustic cavitation

\begin{tabular}{|c|c|c|}
\hline Показатель, \% | Indicator, \% & $\begin{array}{c}\text { Контроль } \\
\text { (без обработки) } \\
\text { Control }\end{array}$ & $\begin{array}{c}\text { Опыт (с применением } \\
\text { высокочастотной } \\
\text { акустической кавитации) } \\
\text { Experiment }\end{array}$ \\
\hline Массовая доля жира| Mass fraction of fat & $22,70 \pm 0,20$ & $21,8 \pm 0,20$ \\
\hline \begin{tabular}{l|l|l} 
Массовая доля жира в сухом веществе & Mass fraction of fat in dry matter
\end{tabular} & $50,57 \pm 0,36$ & $51,32 \pm 0,25$ \\
\hline Массовая доля влаги | Moisture content & $55,11 \pm 0,20$ & $55,11 \pm 0,15$ \\
\hline \begin{tabular}{l|l} 
Массовая доля сухих веществ & Mass fraction of solids \\
\end{tabular} & $44,89 \pm 0,17$ & $45,2 \pm 0,13$ \\
\hline $\begin{array}{l}\text { Массовая доля влаги в обезжиренном веществе } \\
\text { Mass fraction of moisture in a fat-free substance }\end{array}$ & 71,29 & $70,2 \pm 0,20$ \\
\hline \begin{tabular}{l|l|l} 
Массовая доля белка & Mass fraction of protein \\
\end{tabular} & $18,06 \pm 0,19$ & $19,05 \pm 0,10$ \\
\hline
\end{tabular}

При оценке микробиологических показателей брынзы были обнаружены бактерии группы кишечной палочки в контрольном образце, а в обработанном молоке с применением высокочастотной акустической кавитации этой группы микроорганизмов не обнаружено, что свидетельствует об эффективности предложенного метода обработки.
При исследовании жирнокислотного состава брынзы (таблица 2) установлено, что опытный и контрольный образцы имели идентичный состав, из чего можно сделать вывод, что высокочастотная ультразвуковая кавитация не имеет негативного влияния на липидный профиль продукта.

Жирнокислотный состав брынзы, полученной с применением высокочастотной кавитационной обработки коровьего молока, \% от общего содержания жирных кислот

Table 2 .

Fatty Acid composition of cheese obtained with the use of high-frequency cavitation treatment of cow's milk, $\%$ of total fatty acids

\begin{tabular}{|c|c|c|}
\hline \multirow[b]{2}{*}{$\begin{array}{l}\text { Показатель } \\
\text { Indicator }\end{array}$} & \multicolumn{2}{|r|}{ Образцы | Samples } \\
\hline & $\begin{array}{c}\text { Контроль } \\
\text { (без обработки) } \\
\text { Control }\end{array}$ & $\begin{array}{c}\text { Опыт (с применение высокочастотной } \\
\text { акустической кавитации) } \\
\text { Experiment }\end{array}$ \\
\hline Насыщенные: | Saturated: & $70,93 \pm 4,32$ & $71,3 \pm 3,20$ \\
\hline масляная | butyric & $3,01 \pm 0,02$ & $2,99 \pm 0,05$ \\
\hline капроновая | caproic & $2,78 \pm 0,03$ & $2,69 \pm 0,06$ \\
\hline каприловая | caprylic & $1,62 \pm 0,20$ & $1,57 \pm 0,14$ \\
\hline \begin{tabular}{l|l} 
Ненасыщенные & Unsaturated \\
\end{tabular} & $29,07 \pm 1,30$ & $27,29 \pm 1,2$ \\
\hline Мононенасыщенные: | Monounsaturated: & $24,63 \pm 0,14$ & $23,97 \pm 0,28$ \\
\hline \begin{tabular}{r|r} 
олеиновая & oleic \\
\end{tabular} & $18,05 \pm 0,18$ & $17,54 \pm 0,24$ \\
\hline Полиненасыщенные: | Polyunsaturated: & $4,44 \pm 1,30$ & $4,42 \pm 1,20$ \\
\hline линолевая | linoleic & $3,37 \pm 0,02$ & $3,32 \pm 0,01$ \\
\hline линоленовая | linolenic & $0,37 \pm 0,03$ & $0,34 \pm 0,02$ \\
\hline арахидоновая | arachidonic & $0,019 \pm 0,04$ & $0,016 \pm 0,01$ \\
\hline
\end{tabular}

Результаты органолептической оценки свидетельствуют, что контрольные и опытные образцы брынзы не имели видимых пороков, на поверхностности имелись небольшие углубления, вкус у контрольного образца - в меру соленый и кисловатый, у опытного образца более соленый, что, по-видимому, связано с повышенной растворяющей способностью обработанного молока, поэтому для получения заданной степени солености брынзы количество соли должно быть уменьшено на 10-15\%. Таким образом, можно повысить степень экологичности продукта и придать ему функциональную направленность, так как известно, что между потреблением соли и уровнем кровяного давления у человека существует линейная зависимость [15]. У образцов сыров присутствовала однородная консистенция, они имели белый цвет, характерный для молока (рисунок 1).

Согласно ТР ТС 033/2013 г сыр по показателям качества должен отвечать требованиям безопасности [17]. Установлено, что по показателям безопасности образцы брынзы из коровьего молока, подвергнутого высокочастотной кавитационной обработке, соответствовали требуемым значениям нормируемых показателей (таблица 3). 
Таблица 3 .

Показатели безопасности брынзы при использовании высокочастотной кавитационной обработки молока-сырья

Table 3.

Safety Indicators of cheese when using high-frequency cavitation processing of raw milk

\begin{tabular}{|c|c|c|}
\hline $\begin{array}{l}\text { Показатель } \\
\text { Indicator }\end{array}$ & $\begin{array}{c}\text { Контроль (без обработки) } \\
\text { Control }\end{array}$ & $\begin{array}{c}\text { Опыт (с применением высокочастотной } \\
\text { кавитационной обработки) } \\
\text { Experiment } \\
\end{array}$ \\
\hline \multicolumn{3}{|c|}{\begin{tabular}{l|l|l} 
Токсичные элементы & Тохіс \\
\end{tabular}} \\
\hline $\mathrm{Pb}$ & $<0,2$ & $<0,2$ \\
\hline As & $<0,15$ & $<0,15$ \\
\hline $\mathrm{Cd}$ & $<0,1$ & $<0,1$ \\
\hline $\mathrm{Hg}$ & $<0,03$ & $<0,03$ \\
\hline \multicolumn{3}{|c|}{ Пестиициы (в пересчете на жир)|Pesticides (in terms of fat) } \\
\hline $\begin{array}{c}\text { Гексахлорциклогексан ( } \alpha-, \beta-, \gamma \text {-изомеры) } \\
\text { Hexachlorocyclohexane }(\alpha-, \beta-, \gamma \text {-isomers })\end{array}$ & $<0,6$ & $<0,6$ \\
\hline \begin{tabular}{l|l|l} 
ДДТ и его метаболиты & DDT and its metabolites \\
\end{tabular} & $<0,2$ & $<0,2$ \\
\hline \multicolumn{3}{|c|}{\begin{tabular}{l|l|l} 
Aнтибиотики & Antibiotics $*$ \\
\end{tabular}} \\
\hline $\begin{array}{l}\text { Левомицетин (хлорамфеникол) } \\
\text { Levomycetin (chloramphenicol) }\end{array}$ & $<0,0003$ & $<0,0003$ \\
\hline \begin{tabular}{l|l} 
Тетрациклиновая группа & Tetracycline group \\
\end{tabular} & $<0,01$ & $<0,01$ \\
\hline \begin{tabular}{c|c|c|} 
Пенициллины & Penicillins \\
\end{tabular} & $<0,004$ & $<0,004$ \\
\hline \begin{tabular}{l|l|l} 
Стрептомицин & Streptomycin \\
\end{tabular} & $<0,2$ & $<0,2$ \\
\hline \multicolumn{3}{|c|}{\begin{tabular}{l|l} 
Микотоксиньл & Mycotoxins \\
\end{tabular}} \\
\hline $\begin{array}{l}\text { Афлатоксин } \mathrm{M}_{1} \mid \text { Aflatoxin } \mathrm{M}_{1} \\
\end{array}$ & $<0,0005$ & $<0,0005$ \\
\hline
\end{tabular}

Результаты исследования показали целесообразность применения высокочастотной акустической кавитации при производстве рассольного сыра - брынзы. Обработка позволяет уменьшить бактериальную обсемененность молока при этом исключить операцию пастеризации, заменив ее на термизацию. Проведенное экспериментальное исследование доказало эффективность разработанного метода обработки молока, что позволило разработать нормативную документацию ТУ и ТИ 10.51.40-00102068634-2019 «Сыр рассольный «Брынза» с применением высокочастотной кавитационной обработки молока.

\section{Литература}

1 Галстян А.Г. Развитие научных основ и практические решения совершенствования технологий, повышение качества и расширение ассортимента молочных консервов: автореф. дисс. д. тех. н. М., 2009. 50 с.

2 Горбатова К.К. Биохимия молока и молочных продуктов. М.: Легкая и пищевая промышленность, 2004. 344 с.

3 Потороко И.Ю. Научное обоснование и практические аспекты формирования потребительских свойств молочных продуктов, полученных из сырья на территориях техногенного загрязнения: автореф. дисс. д. тех. н. М., 2012. 47 с.

4 Потешкин Н.Г. Потребление соли, артериальная гипертензия и риск развития сосудочно-сердечных заболеваний // Российский коордиологический журнал. 2011. № 7. С.87-95.

5 Тепел А. Химия и физика молока. Спб.: Профессия, 2012. 832 с.

6 Технический регламент на молоко и молочную продукцию: Федеральный закон № 88-Ф3 от 12.06.2008.

7 Тихомирова Н.А., Эль Могази А.Х., Красуля О.Н. и др. Кавитация; энергосбережение в производстве восстановленных молочных продуктов // Переработка молока. 2011. № 7. С. 14-16.

8 Денисова Н.В., Шуварин М.В., Шуварина Н.А. Основные методические подходы к формированию цены на молоко-сырье // Вестник НГИЭИ. 2017. № 8 (75). С. 73-79.

9 Юрова Е.А., Мельденберг Д.Н., Жижин Н.А. Внедрение в лабораторную практику современных методов контроля антибиотиков и остатков ветеринарных лекарственных средств // Молочная промьшленность. 2019. № 1. С. 30-32.

10 Юрова Е.А., Мельденберг Д.Н., Жижин Н.А. Распределение остаточного количества антибиотиков по ходу технологического процесса // Молочная промышленность. 2019. № 2. С. 26-29.

11 Leong T.S.H., Zhou M., Zhou D., Ashokkumar M. et al. The formation of double emulsions in skim milk using minimal food-grade emulsifiers - A comparison between ultrasonic and high pressure homogenisation efficiencies // Journal of Food Engineering. 2017. V. 219. P. 81-92. doi:10.1016/j.jfoodeng.2017.09.018 
12 Barbosa-Cánovas G.V., Ortega-Rivas E., Juliano P., Yan H. Food Powders: Physical Properties, Processing, and Functionality. Food Engineering Series. Kluwer Academic. Plenum Publishers: Springer, 2005. 368 p.

13 Ryabyi V.A., Savinov V.P., Yakunin V.G. Obtaining uniform glow plasma of Capacitive discharge in the area of plasma processing of the substrate // Bulletin of Kazan technological University. 2011. P. 36-40.

\section{References}

1 Galstyan A.G. Development of scientific foundations and practical solutions for improving technology, improving the quality and expanding the range of canned milk. Moscow, 2009. 50 p. (in Russian).

2 Gorbatova K.K. Biochemistry of milk and dairy products. Moscow, Legkaya i pishchevaya promyshlennost', 2004. 344 p. (in Russian).

3 Potoroko I.Yu. Scientifically substantiated and practical aspects of the formation of consumer properties of dairy products obtained from raw materials in the territorial territories of technogenic pollution. Moscow, 2012. 47 p. (in Russian).

4 Poteshkin N.G. Salt intake, arterial hypertension and the risk of developing cardiovascular diseases. Russian Coordination Journal. 2011. no. 7. pp. 87-95. (in Russian).

5 Tepel A. Chemistry and physics of milk. St. Petersburg, Professiya, 2012. 832 p. (in Russian).

6 Technical regulations for milk and dairy products: Federal Law No. 88-FZ of 12.06.2008. (in Russian).

7 Tikhomirova N.A., El Mogazi A.Kh., Krasulya O.N. et al. Cavitation; energy saving in the production of reconstituted dairy products. Milk processing. 2011. no. 7. pp. 14-16. (in Russian).

8 Denisova N.V., Shuvarin M.V., Shuvarina N.A. The main methodological approaches to the formation of prices for raw milk. Bulletin NGIEI. 2017. no. 8 (75). pp. 73-79. (in Russian).

9 Yurova E.A., Meldenberg D.N., Zhizhin N.A. The introduction into the laboratory of modern methods of control of antibiotics and residues of veterinary medicines. Dairy industry. 2019. no. 1. pp. 30-32. (in Russian).

10 Yurova E.A., Meldenberg D.N., Zhizhin N.A. The distribution of the residual amount of antibiotics during the process. Dairy industry. 2019. no. 2. pp. 26-29. (in Russian).

11 Leong T.S.H., Zhou M., Zhou D., Ashokkumar M. et al. The formation of double emulsions in skim milk using minimal food-grade emulsifiers - A comparison between ultrasonic and high pressure homogenisation efficiencies. Journal of Food Engineering. 2017. vol. 219. pp. 81-92. doi:10.1016/j.jfoodeng.2017.09.018

12 Barbosa-Cánovas G.V., Ortega-Rivas E., Juliano P., Yan H. Food Powders: Physical Properties, Processing, and Functionality. Food Engineering Series. Kluwer Academic. Plenum Publishers: Springer, 2005. 368 p.

13 Ryabyi V.A., Savinov V.P., Yakunin V.G. Obtaining uniform glow plasma of Capacitive discharge in the area of plasma processing of the substrate. Bulletin of Kazan technological University. 2011. pp. 36-40.

\section{Сведения об авторах}

Ксения А. Канина аспирант, кафедра технологии хранения и переработки продуктов животноводства, Российский Государственный аграрный университет - МСХА имени К.А. Тимирязева, ул. Тимирязевская, 49, г. Москва, 127550 , Россия, kseniya.kanina.91@mail.ru

(Dhttps://orcid.org/0000-0002-8833-4915

Ольга Н. Красуля д.т.н., профессор, кафедра технологии хранения и переработки продуктов животноводства, Российский Государственный аграрный университет - MCXА имени К.А. Тимирязева, ул. Тимирязевская, 49, г. Москва, 127550, Россия, okrasulya@mail.ru

Dhttps://orcid.org/0000-0002-6234-9609

Николай А. Жижин научный сотрудник, ВНИИ молочной промышленности, ул. Люсиновская, 35/7, г. Москва, 115093 , Россия, zhizhinmoloko@mail.ru

(Dhttps://orcid.org/0000-0002-6690-0488

Елена С. Семенова младший научный сотрудник, ВНИИ молочной промышленности, ул. Люсиновская, 35/7, г. Москва, 115093, Россия, semenovamoloko@mail.ru

\section{Вклад авторов}

Ксения А. Канина написала рукопись, корректировал её до подачи в редакцию, несет ответственность за плагиат

Ольга Н. Красуля предложила методику проведения Николай А. Жижин консультация в ходе исследования Елена С. Семенова обзор литературных источников по исследуемой проблеме

\section{Information about authors}

Ksenia A. Kanina graduate student, technology of storage and processing of animal products department, Russian State Agrarian University - Moscow Timiryazev Agricultural Academy, Timiryazevskaya st., 49, Moscow, 127550, Russia, kseniya.kanina.91@mail.ru

(Dhttps://orcid.org/0000-0002-8833-4915

Olga N. Krasulya Dr. Sci. (Engin.), professor, technology of storage and processing of animal products department, Russian State Agrarian University - Moscow Timiryazev Agricultural Academy, Timiryazevskaya st., 49, Moscow, 127550, Russia, okrasulya@mail.ru

(iDhttps://orcid.org/0000-0002-6234-9609

Nikolay A. Zhizhin researcher, All-Russian Research Institute of Dairy Industry, lyusinovskaya str., 35/7, Moscow, 115093, Russia, zhizhinmoloko@mail.ru

(iDhttps://orcid.org/0000-0002-6690-0488

Elena S. Semenova junior researcher, All-Russian Research Institute of Dairy Industry, lyusinovskaya str., 35/7, Moscow, 115093, Russia, semenovamoloko@mail.ru

\section{Contribution}

Ksenia A. Kanina she wrote the manuscript, corrected it before submitting to the editor, is responsible for plagiarism

Olga N. Krasulya proposed a scheme of the experiment

Nikolay A. Zhizhin consultation during the study

Elena S. Semenova review of the literature on an investigated problem

\section{Conflict of interest}

The authors declare no conflict of interest.

Авторы заявляют об отсутствии конфликта интересов.

Принята в печать 31/08/2019

\begin{tabular}{ccc}
\hline Поступила 02/08/2019 & После редакции 16/08/2019 & Принята в печать 31/08/2019 \\
\hline Received 02/08/2019 & Accepted in revised 16/08/2019 & Accepted 31/08/2019 \\
\hline
\end{tabular}

